\title{
Correction to: Partisan Dehumanization in American
}

\section{Politics}

\author{
Erin C. Cassese ${ }^{1}$
}

Published online: 30 November 2019

(c) Springer Science+Business Media, LLC, part of Springer Nature 2019

\section{Correction to: Political Behavior https://doi.org/10.1007/s11109-019-09545-w}

In the online version of the article, the $y$-axis labels for Figure 1 are incorrect. The Figure 1a y-axis reads "Mechanistic Traits". It should read "Animalistic Traits". The Figure 1b y-axis reads "Animalistic Traits" and should read "Mechanistic Traits". The correct version of Fig. 1 is given below.

The original article can be found online at https://doi.org/10.1007/s11109-019-09545-w.

\section{Erin C. Cassese}

ecassese@udel.edu

1 Department of Political Science and International Relations, University of Delaware, Newark, DE, USA 

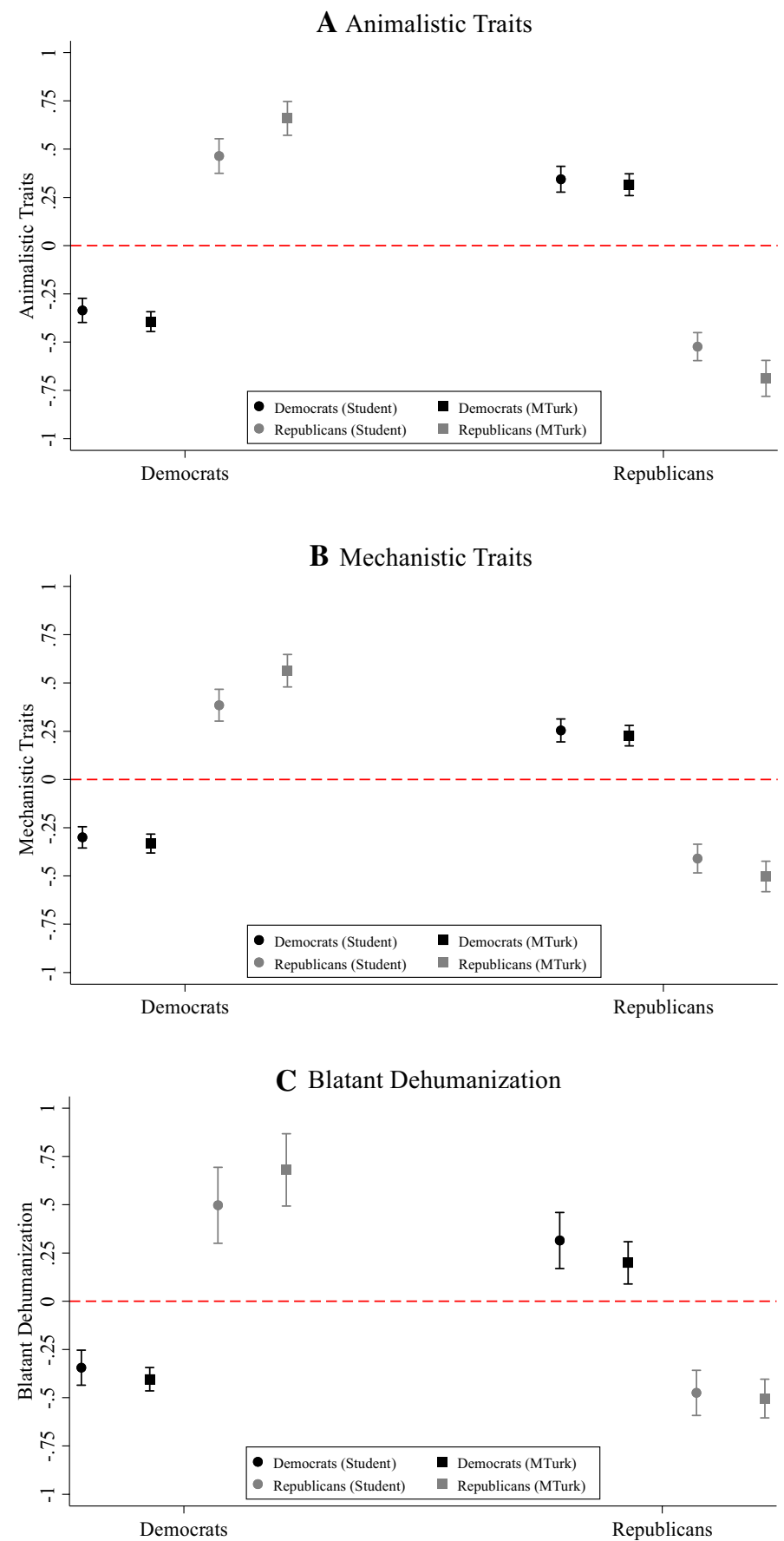

Fig. 1 Dehumanization of the parties across subtle and blatant measures. Note: Entries are mean scale values surrounded by $95 \%$ confidence intervals. A reference line is included at zero, the mean of the standardized scales 
Publisher's Note Springer Nature remains neutral with regard to jurisdictional claims in published maps and institutional affiliations. 